\title{
Optimization in Supply Chain Management, the Current State and Future Directions - A Systematic Review and Bibliometric Analysis
}

\author{
Mahmood Movahedipour ${ }^{1,2}$ (D), Mengke Yang ${ }^{3}$ (D), Jianqiu Zeng ${ }^{1}$ (D), Xiankang Wu ${ }^{4}$ (D), Shafaq Salam ${ }^{1}$ \\ ${ }^{1}$ School of Economic and Management, Beijing University Post and Telecommunications (China) \\ ${ }^{2}$ Academic Center for Education, Culture and Research, (ACECR) (Iran) \\ ${ }^{3}$ School of Automation, Beijing University of Posts and Telecommunications (China) \\ ${ }^{4}$ School of Computer Science, Beijing University of Posts and Telecommunications (China) \\ mahmood.movahedipour@yahoo.com,yangmengke@139.com,13718688489@139.com. \\ wxk.20110229@gmail.com,shafaqsalam@yahoo.com
}

Received: July 2016

Accepted: September 2016

\begin{abstract}
:
Purpose: The purpose of this paper is finding the current state of research and identifies high-potential area for future investigation in optimization in supply chain management.

Design/methodology/approach: In this paper we present Bibliometric and Network analysis to examine current state research on optimization in supply chain management to identify established and emergent research field for future investigation. The systematic research review which we used in our study have not grasp or assess by other researchers on this topic. Firstly, based on our methodology Bibliometric analysis began by identifying 1610 publications raised from scientific journals, included literatures from 1994 to March of 2016. Secondly, we applied PageRank algorithm in our data for citation analysis to indicate the significance of a publication. Thirdly, the topological decision variables analysis is done based on Louvain method for network data clustering, for this proposes we used the rigorous tools.
\end{abstract}

Finding: Based on our Network analysis result, the optimization in supply chain management research can be divided into four clusters/modules that introduced fundamental skill, knowledge, theory, application and method. 
Research limitations/implications: We presented some limitation in our research in some fields which could allow new researchers and practitioners conduct the future research to grow up in different dimensions.

Practical implications: Practitioners or policy maker usually are not familiar with these type researches so this is why mush of these survey remain in theatrical and conceptual. Future investigation needs to play in practical application domain instead stop merely in opinion.

Originality/value: Based on our research, the researchers have more attention to work in conceptual analysis due to other fields but we believe that in facility location problem there many remarkable rooms still exist for future research to development. We also contributed more details in the papers.

Keywords: supply chain management, systematic review, bibliometric, network analysis

\section{Introduction}

In the real world, business is highly competitive and dynamic. The rapid rate of innovation, technology, globalization and consumers expectations are modified the type of worldwide market competitions from traditional supply chains to new competitive supply chains (Scs) (Ponomarov \& Holcomb, 2009). The past recent decades, the growing role of global supply chains was associated with increased interconnectedness among suppliers and manufacturers, which led to higher dependency among firms in the supply chains and a higher level of supply chain complexity.

Supply chain Management (SCM) is monitor processing and system implementation to manage the service and flow of the goods in order to capture maximize the efficiency and value added in SCs. Also SCM spans all operation, storage of raw materials, work-in-process inventory and finishing the goods from starting stage to customer point. Now supply chains network have faced challenges like as high demand variability, short life of products, and different expectations and requirements of customers; adapting to these challenges increased supply chain complexity and resulted in more instability and unpredictability (Stefanovic, Stefanovic \& Radenkovic, 2009)

SCM encompasses three decision levels: strategic, tactical and operative. In particular, in strategic stage, supply chain design comprises the making decisions following to the number and location of production and storage facilities, the amount of capacity at each facility, the conciliation of market demand analyzing and decision making on supplier selection to check out total cost feature (Chopra \& Meindl, 2004). 
In recent years, the number of publication has increased extremely in the supply chain management area; authors found the lack of comprehensive systematic review in SCM. The main aim of our research is to present established survey streams and fertile new research field with potential for future investigation. Network analysis will done after bibliometric analysis to identifying the area which researchers have/have not more attention to. With these tools also we can introduce some clusters for our study to identify emerging relevant area according to researcher and organization characteristics. Using these type literature review, provide opportunity for future survey which did not grasp or assess previously. Our research beginning with identifying more than 2000 papers, after applying refinement and filtering, it reached to 1610 publications. All publications raised from scientific journals, included from 1994 to March of 2016. We used two rigorous software for citation, co-citation and clustering classification analyses to identifying four major clusters. Our systematic review identified different clusters set, for area classification of current models and future insight, to evaluated emergent/mature field of studies.

The reminder of this paper is organized as follows: Section 2, in this section, we introduce our research methodology and clarify to gathering data for bibliometric analysis from organizations, journals and authors. We describe "BibExcel" and "Gephi" as the bibliometric and network analysis software in Section 3 and 4 . In section 4 the assessment of the result is provided. Section 5 presented the conclusion and weakness/limitation in this research, and mentions some suggestion for future direction.

\section{Methods and Procedures}

In Table 1, we tried to show recent literature review which they have dealing with Supply Chain Management in different field and neighboring domains. In column 1 and 2 shows the corresponding paper main topic and 3 column field related to SCM. In order to find out, the method which others researcher use in the recent literature reviews in different part of SCM; we provided Table 1. There are different trend between authors for example see Fabbe-Costes and Jahre (2008), and Meixell and Norbis (2008).

Following to Fahimnia et al. (2015), also we applied bibliometric and network analysis in our paper. Fahimnia et al. (2015) reviewed the Green supply network, the authors analyzed more than 1000 published papers in recent past years, analysis through bibliometric software to showing topical area. Also with co-citation data analysis, they ranked the lead papers in different clusters and introduced 5 main area research. Then shows, the evaluation of survey fields in 5 clusters during 1996 till 2011 with 8 figures. Also our another key paper is Melo et al. (2009), working on location decision-making problem, they emphasized to involved identifying supply chain modeling in decision making strategy 
also they mentioned 37 papers to classified to supply chain decision making to addressing in different typical parts in supply chin such as rout, procurement and inventory. They showed that combination of inventory and production making decision is frequently use in facility location and allocation cases. In another part they taxonomy 18 papers in different network structure respected to closed loop or reverse logistic activity in different layers (Huscroft, Hazen, Hall, Skipper \& Hanna, 2013). They reach this conclusion just few papers concentrated on both closed-loop and forward logistic models comprehensively.

\begin{tabular}{|c|c|c|c|}
\hline Article & Application & Scope & Field \\
\hline \multicolumn{4}{|l|}{ Supply chain management } \\
\hline $\begin{array}{l}\text { (Wang, Wallacen, Shen \& Choi, } \\
\text { 2015) }\end{array}$ & $\begin{array}{l}\text { Finance \& } \\
\text { telecommunication }\end{array}$ & $\begin{array}{l}\text { Two type service: SOSCs } \\
\text { \& PSSCs }\end{array}$ & Service \\
\hline $\begin{array}{l}\text { (Eskandarpour, Dejax, Miemczyk \& } \\
\text { Péton, 2015) }\end{array}$ & $\begin{array}{l}\text { Frameworks } \\
\text { Concept }\end{array}$ & Competitive SCs & $\begin{array}{l}\text { Sustainable/Network } \\
\text { Design }\end{array}$ \\
\hline (Kaufmann \& Gaeckler, 2015) & & Partial Least Square & SCM Structure \\
\hline $\begin{array}{l}\text { (Fahimnia, Sarkis \& Davarzani, } \\
\text { 2015), }\end{array}$ & Further Investigation & $\begin{array}{l}\text { Bibliometric Analysis and } \\
\text { Network analysis }\end{array}$ & Green Supply \\
\hline $\begin{array}{l}\text { (Kundu, Jain, Kumar \& Chandra } \\
\text { 2015) }\end{array}$ & Latent Semantic Analyzing & Behavioral aspects & Behavioral Operations \\
\hline $\begin{array}{l}\text { (Farahani, Rezapour, Drezner \& } \\
\text { Fallah, 2014) }\end{array}$ & Framework Design & Transportation Problem & Network Design \\
\hline $\begin{array}{l}\text { (Martínez-Jurado \& } \\
\text { Moyano-Fuentes, 2014) }\end{array}$ & & Sustainability & Lean Management \\
\hline (Dabbene, Gay \& Tortia, 2014) & $\begin{array}{l}\text { Food Supply Chain } \\
\text { Management }\end{array}$ & Cost-Benefit Analysis & Traceability \\
\hline (Seuring \& Müller, 2008) & Modeling techniques & Quantitative Modeling & Sustainability \\
\hline (Aust \& Buscher, 2014) & Game theory & General Setup modeling & Cooperative Advertising \\
\hline $\begin{array}{l}\text { (Madenasa, Tiwaria, J. Turnera \& } \\
\text { Woodward, 2014) }\end{array}$ & Lifecycle production & Information management & Information Flow \\
\hline (Marra, Ho \& S. Edwards, 2012) & & Sharing process & Knowledge Management \\
\hline (Gupta \& Palsule-Desai, 2011) & $\begin{array}{l}\text { Environmental } \\
\text { consideration }\end{array}$ & $\begin{array}{l}\text { Sustainable Supply Chain } \\
\text { Management (SSCM) }\end{array}$ & Sustainability \\
\hline (Awudu \& Zhang, 2012) & $\begin{array}{l}\text { biofuel supply chain } \\
\text { management }\end{array}$ & & $\begin{array}{l}\text { Uncertainties/Sustainabilit } \\
\mathrm{y}\end{array}$ \\
\hline (Gunasekaran \& Ngaib, 2005) & Mass customization & Frame work of SCM & Build-to-order@sCM \\
\hline (Grieger, 2003) & Electronic commerce & E-economy & Electronic SCM \\
\hline (Sarkis, Zhu \& Lai, 2011) & $\begin{array}{l}\text { Environmental } \\
\text { management systems }\end{array}$ & Organizational theories & Green Supply \\
\hline $\begin{array}{l}\text { (Melo, Nickel \& Saldanha-da-Gama, } \\
\text { 2009) }\end{array}$ & & Location decisions making & Facility Location \\
\hline
\end{tabular}

Table 1. Summarized some reviewed papers in related area 


\subsection{Research Methodology}

The aim of a systematic literature reviews is to direct toward the map of literature to distinguish the gap research to transparent the edge of sciences (Su, Chen \& Yang, 2016). Key words search, literature searching and using different type typical analyzing made the structure of literature review which made by an iterative cycle processing (Saunders, Lewis \& Thornhill, 2009), also (Pazhani, Ventura \& Mendoza, 2016) suggested designing bibliography methodology to building mind road map for structure the literature review. As this approach also we use these steps, introducing the suitable search terms for data collecting and reach to initial result, after refinement and elimination, the result will send to data statistics analysis, at the end comprehensive data evaluation will be done to reach clustering classification to show direction for future scholars in this field.

\subsection{Introducing the Appropriate Research Terms}

Six main keywords are used to starting for our research and data collection. Our keywords are "Supply Chain", "Framework Design", "Sustainable development", “Optimization OR Optimisation”, "Network Design" and "Modeling OR Modelling". Combined these key words including, (1) "Framework Design" AND "Sustainable development" AND "Supply Chain", (2) "Network Design" AND "Sustainable development" AND "Supply Chain”, (3) Optimization OR Optimisation AND "Supply Chain", (4) Modeling OR Modelling AND "Supply Chain". There are different decisions - making in supply chain network design but suppose that the most important one is facility locating in different layers of supply chain (Eskandarpour et al., 2015), in continue perhaps logistics system configuration, re-organization, outsourcing modelling and re-configuration are critical issue in supply chain networks optimization. Using different method of optimization for taking these strategical decisions are essential for supply chain network design. So authors believe that with employ of these keywords will completely cover the main interest.

\subsection{Initial Research}

For defining our research terms, using "Abstract, Title and Keywords" in advance research of electronic bibliographical sources Web of Science, in this survey we refine or search based on "journal" and all the articles saved, but "Conference paper, Book and Chapter of book" is not included. Based on this refining, our initial research result achieve 2196 articles totally. The breakdown of research result is shown in Table 2. Web of Science Database web site could save essential information in different formats like as RIS and Plaintext. With the export the related file from Web site, we accesses the all information such as, references and author's names, Citations and abstracts. 


\begin{tabular}{|l|r|r|}
\hline Research Key Words & $\begin{array}{r}\text { Result of Search } \\
\text { (Papers) }\end{array}$ & $\begin{array}{c}\text { Result of Search } \\
\text { after refinement } \\
\text { (Papers) }\end{array}$ \\
\hline "Framework Design” AND “Sustainable development” AND “Supply Chain” & 203 & 178 \\
\hline "Network Design” AND “Sustainable development” AND “Supply Chain” & 194 & 134 \\
\hline Optimization OR Optimisation AND “Supply Chain” & 1170 & 845 \\
\hline Modeling OR Modelling AND “Supply Chain” & 602 & 453 \\
\hline Total & 2196 & 1610 \\
\hline
\end{tabular}

Table 2. The initial researching result before and after refinement

\subsection{Research Refining Result}

It is clear that from 2196 papers many of them could be appears more than one time in different category. Also we faced some few papers that may not be as scientific field, same as non- refereed papers or published in nonscientific magazines and unknown author's names. To solve this problem we used Endnote software, at first imported RIS file from Web of Science to Endnote then elimination done totally with this software and again convert it to RIS format for future analyzing. After elimination, our result remains 1610 unique ones. Table 2 shows our observation after refinement related to each four research division. Our record started from beginning of 1994 till the end of March 2016, during in these years and based on Figure 1 we see that from the start of our research study, till 2010 the numbers of articles which published in this filed grow up smoothly. But in 2010 published papers increased tremendously, it jumped fast which in 2012 the numbers of papers is shown in graph is nearby 4 times due to 2010. Given that the first debate on facility location and supply chin network is traced to before 1980s (Melo et al., 2009) it is not surprise that in our observation be the same as Figure 1.

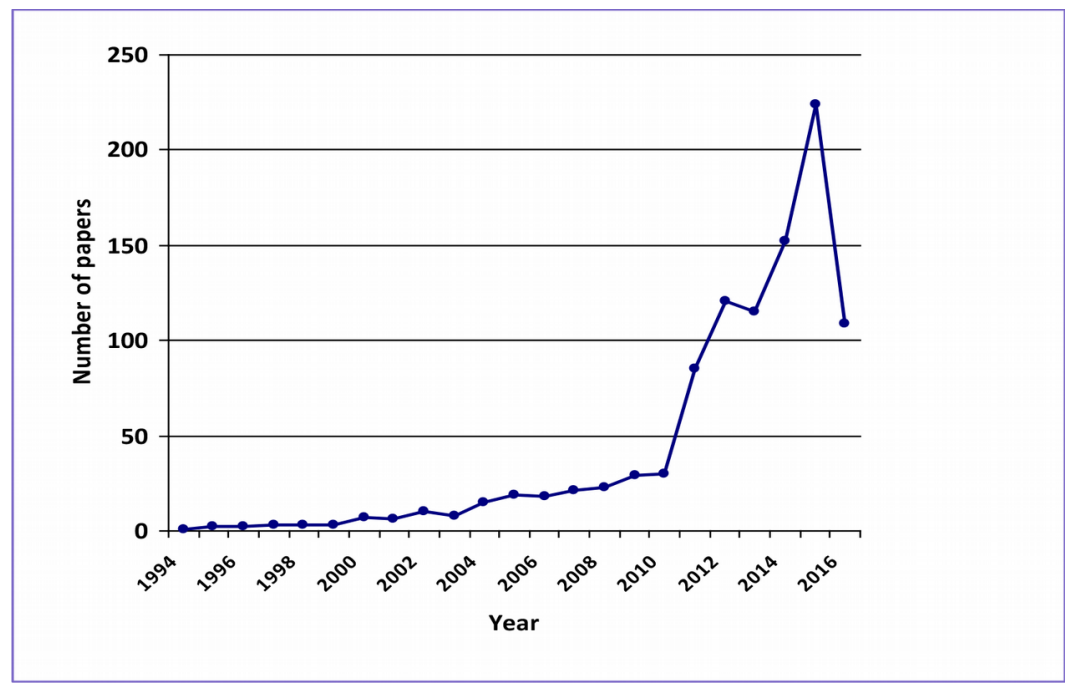

Figure 1. Articles trend in the field of our review 


\subsection{Initial Statistic Data}

Figure 1 shows the numbers of article trend in optimization in supply chain network. In our first survey shows that all the 1610 papers published in 501 journals, the 11 top journals which published at least 10 articles during in 22-years ago is appeared in Table 3. We found that 308 identified papers published in these 11 journals, it is about $20 \%$ of all papers publication. Also there are some more statistic data for each journal which we did not present in Table 3, such as self-citation rate. The value of self-citation index use for visibility and scientific authority. For example both International Journal of Production Economics and European Journal of Operational journals which show in the top of list, have high level ranking among the others.

\begin{tabular}{|c|c|c|c|c|c|c|c|c|c|c|c|c|c|c|c|c|c|c|c|c|c|c|c|c|}
\hline \multirow[b]{2}{*}{ Journals } & \multicolumn{24}{|c|}{ Publication Year } \\
\hline & 롱 & इ & ஜ̊ & ஜั & ล̀ & $\stackrel{\infty}{2}$ & ลे & ชి & 홍 & ชิ & ชి & मे & กิ & ชి & 옹 & ஓి & हे & 응 & 훙 & ำ & ๓⿳亠े冖 & 官 & ำ: & $\begin{array}{l}\frac{2}{0} \\
\frac{0}{3} \\
\frac{3}{2} \\
\frac{0}{2} \\
\text { ते }\end{array}$ \\
\hline $\begin{array}{l}\text { International Journal of } \\
\text { Production Economics }\end{array}$ & 71 & 1 & 1 & & 2 & 2 & 1 & 2 & 2 & 3 & 2 & 2 & 2 & 2 & 1 & 1 & 3 & 5 & 5 & 5 & 2 & 10 & 12 & 5 \\
\hline $\begin{array}{l}\text { European Journal of } \\
\text { Operational Research }\end{array}$ & 61 & & 1 & 1 & 1 & 1 & & 1 & & 2 & 4 & 2 & 1 & 1 & 2 & 2 & 4 & 4 & 3 & 6 & 3 & 7 & 11 & 4 \\
\hline $\begin{array}{l}\text { Computers \& Industrial } \\
\text { Engineering }\end{array}$ & 34 & & & & & & & & & & & 2 & & 1 & & 1 & 2 & 3 & & & 2 & 4 & 16 & 3 \\
\hline $\begin{array}{l}\text { Expert Systems with } \\
\text { Applications }\end{array}$ & 28 & & & & & & & & & & 1 & & & & 1 & 1 & 4 & 4 & 3 & 4 & & 4 & 4 & 2 \\
\hline $\begin{array}{l}\text { Journal of Cleaner } \\
\text { Production }\end{array}$ & 23 & & & & & & & & & & & & 1 & & & & 1 & 1 & & 2 & 3 & 2 & 8 & 5 \\
\hline $\begin{array}{l}\text { Transportation Research } \\
\text { Part E: Logistics and } \\
\text { Transportation Review }\end{array}$ & 22 & & & & & & 1 & & & & & 1 & & & & 1 & & 1 & 1 & 1 & 2 & 5 & 5 & 4 \\
\hline $\begin{array}{l}\text { Applied Mathematical } \\
\text { Modeling }\end{array}$ & 18 & & & & & & & & & & & & & & & & 1 & & 1 & 2 & 1 & 5 & 6 & 2 \\
\hline Omega & 15 & & & 1 & & & & & & & & & 1 & & 1 & & 1 & 1 & 2 & & 2 & 2 & 3 & 1 \\
\hline $\begin{array}{l}\text { Journal of } \\
\text { Manufacturing Systems }\end{array}$ & 14 & & & & & & & & & & & & & & & 1 & & 1 & & & 1 & & 8 & 3 \\
\hline Procedia CIRP & 12 & & & & & & & & & & & & & & & & & & & & 2 & 4 & 4 & 2 \\
\hline $\begin{array}{l}\text { Computers \& } \\
\text { Operations Research }\end{array}$ & 10 & & & & & & & & & & & & & 1 & 1 & & 1 & & & & 1 & 1 & 5 & \\
\hline Total & 308 & 1 & 2 & 2 & 3 & 3 & 2 & 3 & 2 & 5 & 7 & 7 & 5 & 5 & 6 & 7 & 17 & 20 & 15 & 20 & 19 & 44 & 82 & 31 \\
\hline
\end{tabular}

Table 3. The 11 top journals with 10 or more publications in location facility in supply chain management area 


\subsection{Data Processing}

Bibliometric is systematic way to help us to measure the impact of scientific publications. Also with context of this toolkit the impact of scholar and productivity is measured by the number of citation with bibliometric. Our data processing divided in two sections; first it started with bibliometric analysis and then network analysis which presented in section 4 and 5 respectively. We used BibExcel software package to bibliometric analysis, it could provide easily statistics data such as title, author, abstract, research area, topic and affiliation. BibExcel selected among the other software package because of its flexibility and compatibility with the some application like as Gephi and Pajek (Costa, Celano, Fichera \& Trovato, 2010). After bibliometric processing all data conduct to network analysis, Pajek (Dabkowski, Breiger \& Szidarovszky, 2015) VOSviewer (Jie, Xiaohong, Shifei \& Jovanovic, 2014) and Gephi (Beiler, 2016) are existing software package for literature network analysis. Gephi is exploration and leading visualization free open-source package for all type networks and could runs on different operating system. We chose Gephi as network analysis software due to high capability to visualization in various graph (Wehbe, Hattab \& Hamzeh, 2016) and efficiently to work with dataset.

\section{Bibliometric Analysis Method}

There are some popular software package for bibliometric analysis which many scholar used them for research and study, such as, SITKIS (Artto, Martinsuo, Gemünden \& Murtoaro, 2009), NVivo (Lu \& Yuan, 2011), Citespace (Chen, Liu, Luo, Webber \& Chen, 2016), Network workbench (Gomez-Jauregui, Gomez-Jauregui, Manchado \& Otero, 2014), HistCite (Garfield, 2009) Publish or Perish (Hall, 2011), BibExcel (Fahimnia et al., 2015). Each of these software has special ability, for example: Citespace is designed as a toolkit for analyzing trend and progressive knowledge filed visualization and HistCite is a tool to make historiographical diagrams get direct from citations.

Furthermore based on our requirement for future steps, we were looking for powerful software with high level degree flexibility to analysis comprehensive information and convert input data from different online database like as Web of Science and Science of Direct systematically. Also it should have enough ability to generated data output files can be imported to Microsoft Excel and network analysis software in Gephi. BibExcel designed to easy assist a user in bibliometric analyzing data, or any data of a textual nature formatted in a similar manner. This toolkit enables the generation of data files that can be imported to Excel or any program that further processes or visualizes tabbed data records. As above explanation we have chosen BibExcel software for our study. 
The output searching in Web of Science has different file format, we selected RIS format with full record content which BibExcel could extract the bibliographic information. Our study is concentrated on following information: Journal name, location of organization, authors name, key words and reference. In continue 3 below section will show the output files of BibExcel analysis to provide statistic data.

\subsection{Ranking of Authors in Our Study}

The input data of bibliographic can be sort and analysis by BibExcel; it has some toolbars which help us to extract different data from RIS file. Table 4 shows the top 15 contribution authors with 8 or more publication in our records; also beside of each we mentioned the number of publication. It is clear to see that Shah and Tiwari are in high raking in this table and dominated over the list.

\begin{tabular}{|l|r|}
\hline Authors & $\begin{array}{c}\text { Result of Search } \\
\text { (Papers) }\end{array}$ \\
\hline Shah, Nilay & 20 \\
\hline Tiwari, M. K. & 13 \\
\hline Farahani, Reza Zanjirani & 13 \\
\hline Rezapour, Shabnam & 11 \\
\hline Papageorgiou, Lazaros G. & 11 \\
\hline Niaki, Seyed Taghi Akhavan & 11 \\
\hline Puigjaner, Luis & 11 \\
\hline Diabat, Ali & 10 \\
\hline Pishvaee, Mir Saman & 9 \\
\hline Guillén-Gosálbez, Gonzalo & 8 \\
\hline Torabi, S. A. & 8 \\
\hline Lam, Hon Loong & 8 \\
\hline Grossmann, Ignacio E. & 8 \\
\hline Bezzo, Fabrizio & 158 \\
\hline You, Fengqi & 9 \\
\hline Total & 9 \\
\hline
\end{tabular}

Table 4. The authors with 8 or more publication

Based on our records, this point should be consider Shah and Tiwari in large number of papers are co-authors, they cooperated in the publication as the second or third author, in the other hand Farahani and Rezapour co-authors with each other in many publication. Shah focuses on industry 
processing in supply chain network, planning and scheduling, future challenging and infrastructure design especially in chemical industry. Tiwari with engineering background, study in computational Intelligence in manufacturing and logistics. Farahani and Rezapour contributed on facility location and distribution planning, transportation planning, graph theory, production operations management. In the middle of list Papageorgiou with 11 number publication works on these fields: chemical engineering, biotechnology, mathematics modeling and distributed energy resources. Less than $1 \%$ of all publication is provided by these 15 top authors. Majority leading scholars in this list tend to study in optimization in different section of supply chain network issue, such as network design, mathematical approach and production plan. Grossmann and Lam have published some papers in the field of process systems engineering and green sustainable and broad mathematical programming tools in sustainable processes. The other researcher usually trend to work on general modeling framework, empirical approach and environment issue. For example, Pishvaee used fuzzy theory in his case study and using multi-objective optimization in environmental supply chain network design.

\subsection{Affiliation}

One of the ability of BibExcel is extracting the city of each organization from RIS files. For this order, we sort our data based on "AD tag" in BibExcel and set the other toolbar as BibExcel comment, the output result will be a window which present the affiliation of authors in one column. We could easily export this data to Microsoft Excel for future process. After this stage the analyzed data conduct to GPS (Global Positioning System) visualizer web site for built multiple geocodes, for this purpose we used the "gpsvisualizer.com" web site. It is free GPS visualizer online to make maps from geographic data, there is some limitation to draw a map for multiple geocodes but with asking keyword mapping from Google Map or Bing Map website we could create our geographical map with large number of cities. Figure 2 shows the map which created by "GPSvisualizer" online website, it shows the institutions location which working on optimization in supply chain network. The large numbers of literatures is located in western country in Europe and then west states in USA, also the numbers of publication in west of Asia is impressive. In Figure 2 the diameter of each circle express the relative degree of each institution to the contribution. In general view, the map geographical distribution of these institutions expresses that location facility in supply chain network attracted many researcher around the world. 


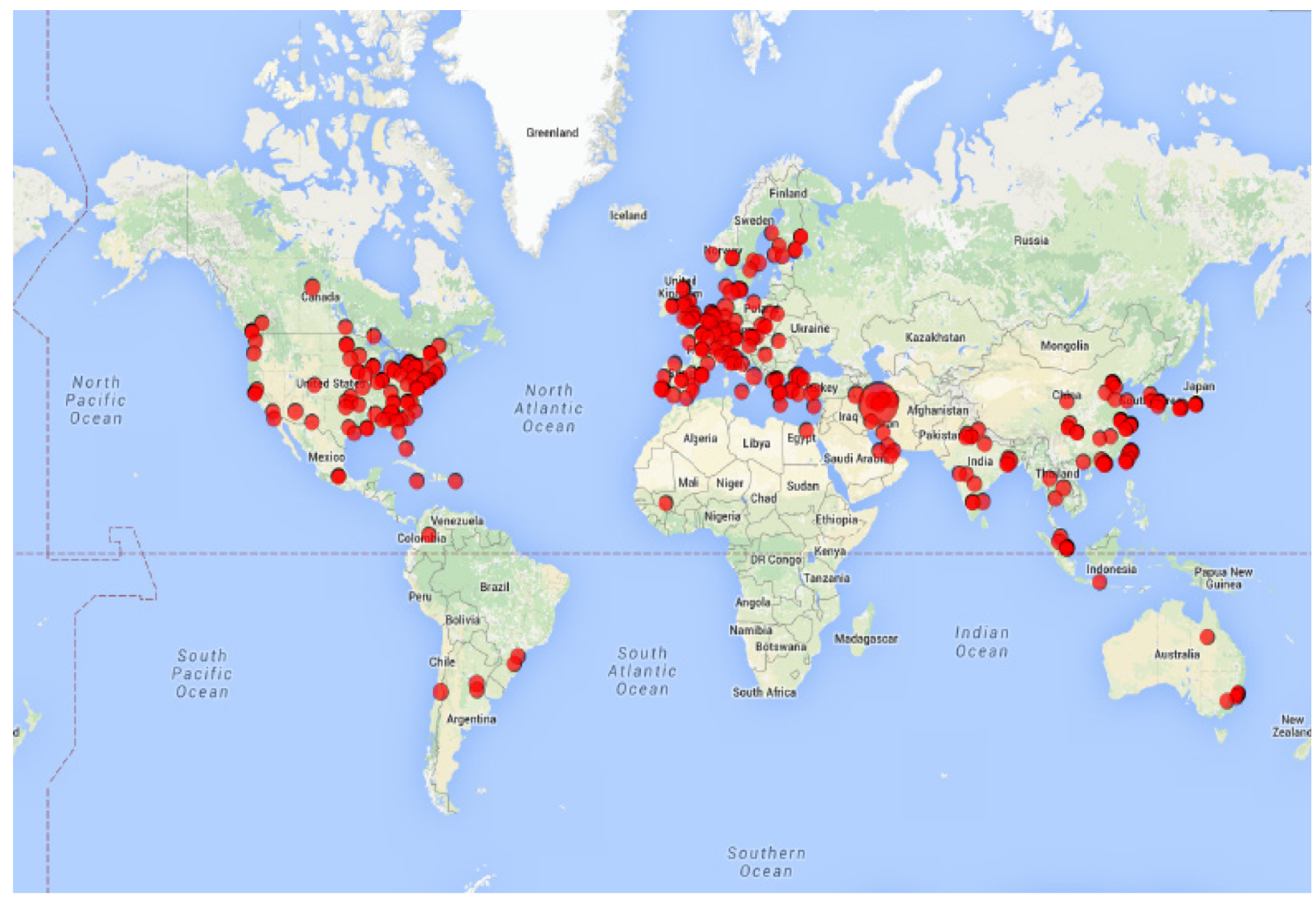

Figure 2. (Red circles) graphical location of all institutions

Table 5 shows greater breakdown in geographical area in globe, like as Europe, USA and Asia. Also we add Oceania and Canada to this list, the remain of the country and the articles without affiliation records indicated in 4 and 5 row, respectively.

\begin{tabular}{|l|r|r|}
\hline Institutions location & Number of publication & Percentage (\%) \\
\hline Europe & 663 & 41.11 \\
\hline United States and Canada & 554 & 34.40 \\
\hline Asia & 290 & 18.01 \\
\hline Oceania & 43 & 2.67 \\
\hline Rest of Globe & 25 & 1.55 \\
\hline No affiliation in Web of Science records & 35 & 2.17 \\
\hline
\end{tabular}

Table 5. Contribution of Institutions based on geographical area

The 18 top institutions with most contributed for publication is mentioned in Table 6. Consider with this table and Table 4, we see that Imperial College London, Indian Institute of Technology and Amirkabir 
University of Technology are presented productively scholars with Shah, Tiwari and Farahani. It should be noted during several years, different publication for one researcher may have submitted from different organization.

\begin{tabular}{|l|r|c|}
\hline Organization & Number of publications & Country \\
\hline University of Tehran & 34 & Iran \\
\hline Georgia Institute of Technology & 27 & United States \\
\hline Hong Kong Polytechnic University & 18 & Hong Kong \\
\hline Eindhoven University of Technology & 15 & Netherland \\
\hline Amirkabir University of Technology & 13 & Iran \\
\hline Imperial College London & 15 & United Kingdom \\
\hline National Taipei University of Technology & 13 & Taiwan \\
\hline Dokuz Eylul University & 8 & Turkey \\
\hline Southeast University & 8 & China \\
\hline National Chiao Tung University & 8 & Taiwan \\
\hline Pennsylvania State University & 7 & United States \\
\hline University of Southern Denmark & 7 & Denmark \\
\hline Indian Institute of Technology & 7 & India \\
\hline Yildiz Technical University & 6 & Turkey \\
\hline North Dakota State University & 6 & United States \\
\hline Nanyang Technological University & 6 & Singapore \\
\hline Chung Yuan Christian University & 6 & Taiwan \\
\hline
\end{tabular}

Table 6 . The 17 top organizations with 6 or more publication

\subsection{Most Common Words Statistics}

In this section we analyzed our data based on most popular words and phrases which used in the title/keyword of articles. The top 13 words used in the title and top 12 words or phrases used in keywords of papers are indicated in Table 7 and Table 8 respectively. With the compare of these tables we observe uniformity of the nature between them, such as: sustainable supply chain management, nonlinear programming optimization and life-cycle assessment. Clearly, it is not strange that all the chosen keywords in this research appear in both tables and also "Optimization" is most interesting word which appear is both lists, our implication is: in the supply chain, network optimization is absolutely necessary for effectiveness. 


\begin{tabular}{|l|r|}
\hline Word & \multicolumn{2}{|c|}{ Repetition } \\
\hline Supply chain & 702 \\
\hline Network & 371 \\
\hline Design & 370 \\
\hline Optimization & 288 \\
\hline Management & 197 \\
\hline Planning & 130 \\
\hline Production & 122 \\
\hline Location & 116 \\
\hline Integrated & 111 \\
\hline Algorithm & 97 \\
\hline Analysis & 80 \\
\hline Inventory & 65 \\
\hline Logistic & 51 \\
\hline
\end{tabular}

Table 7. The most common words in title of articles

\begin{tabular}{|l|r|}
\hline Word & \multicolumn{2}{|c|}{ Repetition } \\
\hline Supply chain management & 265 \\
\hline Linear programming & 197 \\
\hline Close-loop & 123 \\
\hline Modeling & 89 \\
\hline Robust optimization & 65 \\
\hline Life-Cycle & 45 \\
\hline Allocation & 42 \\
\hline Uncertainty & 39 \\
\hline Facility location & 35 \\
\hline Green supply chain & 31 \\
\hline Logistic & 27 \\
\hline Sustainable supply chain & 24 \\
\hline
\end{tabular}

Table 8. The most common words in keywords of articles

\section{Network Analysis}

Now after Bibliometric analysis we continue our study with network analysis in this section. Publication network analysis is the process of graphical investigation though the defined algorithms and graphical theories. For this purpose different software can be employ, but four toolkits are more familiar for researchers, these packages consist of: HistCite Graph maker, VOSviewer, Gephi and Pajek. Each of them has many toolboxes with different flexibility for example: VOSviewer is a comprehensive view on the scientific activities software for visualizing, mapping and clustering techniques in networks analyzing, it could import directly data from Web of Science and Scopus and supported RIS file. Gephi is an open source Windows software, proper for large network, it could analysis and visualization millions of vectors in any networks system. It implemented in Delphi (Pascal) and just accepted ".Net" format, beside the citation network and internet network, one of the most popular usage of Pajek is identifying social roles in Social Network Analysis, e.g. see (Doreian, 2006) and (Dabkowski et al., 2015) for more review see (Batagelj \& Mrvar, 2011). Gephi is visualization, exploration and manipulating toolkit for many kinds of graphs and networks. It is open source software also we can count these main features for Gephi: analysis the Biological Network, ability to import many different file format such as GEXF, NET, GML and GDF (Gephi, 2013). For our study we selected Gephi as our network analysis software, because the design of this package is much broader performance to having a usual distinct toolkit, we doubted that maybe Gephi being user unfriendly but we found it designed very logical structure with ease functionality but user should understand the command sequences during to working with Gephi. 
The bibliographic output file which getting from the Web of Science, is in RIS format, these files cannot use directly to Gephi software. For this order, we need one mediator software to create dataset, BibExcel used as operator for reformatted the data and present graphic dataset. For this purpose different information such as authors names and references extracted from BibExcel then based on the software instruction we continue to reach output files: “.NET” which it need for Gephi for network analysis. With the Web of Science bibliographic output we could conduct our study for citation analysis too.

\subsection{Citation Analysis}

Citation analysis is a systematic way of measuring the relative importance an author or a publication by counting the number of times that author and publication has been cited by other, for this purpose 1610 nodes is created to examine the grade of connection between each node. The primary output of Gephi revealed that near $45 \%$ of all publication cited to each. Table 9 shows 13 publications with most citation in Web of Science database. "Average per Year" is the quantity number of local citation divided to the number of years from publication in Web of Science, "Reference Citation" show the number which each paper cited within 1610 paper-network, "Global Citation in all databases" means number of times which mentioned paper cited among all of Web of Science data base such as: "SciELO Citation Index" and "Chinese Science citation", and "Web of Science Core collection" is the overall Web of Science citation for publication. As it shown in Table 9, the rank of papers in "Global Citation in all databases" is more or less the same as "Reference Citation", it maybe means that that selection of keywords is done with proper way. Another point is the huge difference numbers between these two columns indicated that optimization in supply chain management got more attention from authors in different disciplines. We see that in Table 9 (Melo et al., 2009) dominated the list but following to Table 4 his name is not in the 15 top authors but also in this list we see Shah, Pishvaee \& Torabi as 15 top authors. In Table 9 (Melo et al., 2009) is the top of all columns, it seems that, the invited review which made by Melo and S. Nickel, presented significant contribution of integration local decision with other strategic decisions and received huge attention between researcher. Also the average citation per year for this paper is near two times duo to second paper.

Pishvaee \& Torabi who have co-authored represented three out of 13 high cited publication in Table 9, both of them also did these study in the University of Tehran which this university has highest ranking between in top institutes in our research study (see Table 6 and Figure 2). Both of them have engineering background and working on different type numerical experiments method optimization. Also it is not surprising to see that in Table 9, 4 out all top global cited papers published in "European Journal Of Operational Research" in Table 3 we saw that this journal has second top ranking in publication with 61 papers publication. Table 9 indicated all top cited papers at least published 5 years ago so maybe in near future some papers with high average citation per year will be replaced with in Table 9. Interestingly, we 
see that 8 out of ten top cited papers published in journal which their filed is Engineering/Mathematic, this evidence shows that perhaps in optimization for supply chain management still we need more intensive research as strategic supply chain planning due to solution method.

\begin{tabular}{|c|c|c|c|c|c|}
\hline Author & $\begin{array}{l}\text { Average } \\
\text { per Year }\end{array}$ & $\begin{array}{l}\text { Reference } \\
\text { Citation }\end{array}$ & $\begin{array}{l}\text { Global } \\
\text { Citation }\end{array}$ & $\begin{array}{l}\text { Web of Science } \\
\text { Core }\end{array}$ & Journal Name \\
\hline (Melo et al., 2009) & 48.5 & 136 & 388 & 372 & $\begin{array}{l}\text { European Journal Of } \\
\text { Operational Research }\end{array}$ \\
\hline (Pishvaee \& Torabi, 2010) & 23.85 & 65 & 310 & 303 & Value In Health \\
\hline (Sarkis et al., 2011) & 25.25 & 33 & 303 & 288 & $\begin{array}{l}\text { European Journal Of } \\
\text { Operational Research }\end{array}$ \\
\hline (Yang, Wang \& Li, 2009) & 12.5 & 52 & 200 & 195 & $\begin{array}{l}\text { Industrial \& Engineering } \\
\text { Chemistry Research }\end{array}$ \\
\hline (Hugo \& Pistikopoulos, 2005) & 13.7 & 54 & 158 & 156 & $\begin{array}{l}\text { Journal Of Cleaner } \\
\text { Production }\end{array}$ \\
\hline $\begin{array}{l}\text { (Altiparmak, Gen, Lin \& Paksoy, } \\
\text { 2006) }\end{array}$ & 12.15 & 26 & 158 & 144 & $\begin{array}{l}\text { Computers \& Chemical } \\
\text { Engineering }\end{array}$ \\
\hline (Chen \& He, 2016) & 12.73 & 11 & 140 & 132 & $\begin{array}{l}\text { European Journal Of } \\
\text { Operational Research }\end{array}$ \\
\hline (Hsu \& Chen, 2007) & 9.75 & 19 & 134 & 128 & $\begin{array}{l}\text { Computers \& Chemical } \\
\text { Engineering }\end{array}$ \\
\hline $\begin{array}{l}\text { (Uchimaru, Hazama, Fujiwara \& } \\
\text { Kano, 2015) }\end{array}$ & 13.44 & 35 & 121 & 117 & $\begin{array}{l}\text { Omega-International Journal } \\
\text { Of Management Science }\end{array}$ \\
\hline $\begin{array}{l}\text { (Gajdoš, Ježowicz, Uher \& } \\
\text { Dohnálek, 2016) }\end{array}$ & 12.89 & 41 & 116 & 112 & $\begin{array}{l}\text { International Journal Of } \\
\text { Technology Assessment In } \\
\text { Health Care }\end{array}$ \\
\hline $\begin{array}{l}\text { (Gu, Goetschalckx \& McGinnis, } \\
\text { 2007) }\end{array}$ & 10.36 & 30 & 114 & 106 & $\begin{array}{l}\text { Computers \& Industrial } \\
\text { Engineering }\end{array}$ \\
\hline $\begin{array}{l}\text { (Wang, Liang, Jia, Ge, Xue \& } \\
\text { Wang, 2016) }\end{array}$ & 18.17 & 38 & 109 & 97 & $\begin{array}{l}\text { Applied Mathematical } \\
\text { Modelling }\end{array}$ \\
\hline (Pishvaee \& Torabi, 2010) & 15 & 46 & 105 & 101 & Fuzzy Sets And Systems \\
\hline
\end{tabular}

Table 9. Top authors with more global citation in Web of Science Core database

\subsection{PageRank Analysis}

Very usual method for understanding the level of paper is to counting the number of citation in different database which we indicated in section 4. 1, but also there is a evaluated model to measure average accuracy in in dataset. (Buckley \& Voorhees, 2005) explained "MAP" - Mean Average Precision - based on probabilistic model (Huang, Huang, Wn, An, Liu \& Poon, 2006) with citation graph using, e.g. see Figure 4. C, the papers represented as nodes and citation between the papers indicated as directed edge. So, with apply linkage analysis algorithm in citation graph the ranking grade of each node/paper could be computed. There are three famous linkage analysis algorithm to measuring the publication significance 
(Yin, Huang \& Li, 2011): Degree Distribution, HITS and PageRank. Degree Distribution, this linkage analysis algorithm uses the definition of "Popularity of a document". It means the number of citation for each paper show the ranking of paper (Borodin, Roberts, Rosenthal \& Tsaparas, 2005). For first time HITS (Hyperlink-Induced Topic Search) presented by (Kleinberg, 1999), the idea behind of this algorithm is computing the importance of deferent type of Web Pages. We have two type attributes for identifying the importance of Web Pages, hub and authority, hub attribute record the page quality as useful resources and authority attribute record the page quality as source itself. These two authorities could compatible to paper citation network analysis. In general world we can say that "PageRank algorithm" is a new version of "Degree Distribution algorithm" which considers separated weight for each node/paper. In our study we used Page Rank algorithm as publication network analyzer.

Page Rank algorithm presented by Larry Page and Sergey Brain in 1998. The primary application of PageRank was ranking web pages in Google based on the keywords searching to indicated page's relevance or importance and indicated the relationship between them, also, many authors study the Search Engine Optimization (SEO) topics based on Page Rank algorithm. These properties could the expanding to explore in citation network. The PageRank algorithms formula with $\mathrm{N}$ publication is:

$$
P R(A)=\frac{1-d}{N}+d * \sum_{i} \frac{P R\left(T_{i}\right)}{C\left(T_{i}\right)}
$$

Where

$\operatorname{PR}(A)$, donated PageRank of paper $A$ which has been cited by paper $T_{i}$ in the citation network.

$C\left(T_{i}\right)$, presented the number of citation in $T_{i}$.

$d \in[0,1]$, damping factor, with residual probability damping factor defined as 0.85 (Yin et al., 2011).

$N$, the number of publication in citation network.

Attention if $C\left(T_{i}\right)=0$ then in above formula, the number of publication will be instead of $C\left(T_{i}\right)$.

Now if we consideration PageRank for $P_{1}, \mathrm{P}_{2}, \ldots, \mathrm{P}_{N}$, the equation is as fallow:

$$
P R\left(p_{i}\right)=\frac{1-d}{N}+d * \sum_{p_{j} \in M\left(p_{i}\right)} \frac{P R\left(p_{j}\right)}{C\left(p_{j}\right)}
$$

$M\left(p_{i}\right)$ is the set of papers which cited to $p_{i}$.

$C\left(p_{j}\right)$ is the number of citation on $p_{j}$.

$P R\left(p_{i}\right)$ PageRank value of $p_{i}$ 
$\operatorname{PR}\left(p_{j}\right)$ PageRank value of $p_{j}$.

In this case we need to introduce eigenvector. $P R\left(p_{i}\right)$ numbers dominated in right of eigenvector, this made PageRank a practically proper metric.

The eigenvector is:

$$
\begin{aligned}
& R=\left(\begin{array}{c}
P R\left(p_{1}\right) \\
P A\left(p_{2}\right) \\
\vdots \\
P R\left(p_{N}\right)
\end{array}\right) \quad R=\left(\begin{array}{c}
(1-d) / N \\
(1-d) / N \\
\vdots \\
(1-d) / N
\end{array}\right)+d *\left(\begin{array}{ccc}
l\left(p_{1}, p_{1}\right) & & l\left(p_{1}, p_{N}\right) \\
l\left(p_{2}, p_{1}\right) & \ldots & l\left(p_{2}, p_{N}\right) \\
\vdots & l\left(p_{i}, p_{j}\right) & \vdots \\
l\left(p_{N}, p_{1}\right) & \ldots & l\left(p_{N}, p_{N}\right) \\
& &
\end{array}\right) \\
& \sum_{i=1}^{N} l\left(p_{i}, p_{j}\right)=1
\end{aligned}
$$

In Table 10 pretest the 10 top PageRank value in our study. With consider Table 9 and 10 we find that seven of publications are the same, these publications included, as new item in Table 10 (Papageorgiou, 2009), (Costa et al., 2010) and (Prakash \& Deshmukh, 2011). These paper published after 2005 and cited by high-cited papers. The interesting point is, not only these three papers (Costa et al., 2010), (Pishvaee \& Torabi, 2010) and (Sarkis et al., 2011) located in both tables (Table 9 and Table10) also they published after 2010. The outcome of this section given us the impact of citation from the high-cited publication is greatly important for PageRank algorithm and also can see that maybe PageRank give us better general view as prestige of papers. Although this topic is most popular between the researchers and discuss by expert to explore to find new solution for more accuracy in this field for example see (González-Pereira, Guerrero-Bote \& Moya-Anegón, 2010)

\begin{tabular}{|l|r|r|r|}
\hline Author & PageRank & Global Citation & Local citation \\
\hline (Costa et al., 2010) & 0.0342 & 158 & 54 \\
\hline (Papageorgiou, 2009) & 0.0223 & 88 & 22 \\
\hline (Melo et al., 2009) & 0.0212 & 388 & 136 \\
\hline (Costa et al., 2010) & 0.0196 & 53 & 8 \\
\hline (Pishvaee \& Torabi, 2010) & 0.0176 & 310 & 65 \\
\hline (Sarkis et al., 2011) & 0.0134 & 303 & 33 \\
\hline (Prakash \& Deshmukh, 2011) & 0.0845 & 132 & 16 \\
\hline (Altiparmak et al., 2006) & 0.0832 & 114 & 30 \\
\hline (Amiri, 2006) & 0.0078 & 140 & 11 \\
\hline (Gajdoš et al., 2016) & 0.0067 & 116 & 41 \\
\hline
\end{tabular}

Table 10. The top authors with 8 or more articles with PageRank value 


\subsection{Co-citation Analysis}

Henry Small proposed the co-citation in 1973 (Small, 1973). Co-citation analysis is an assessment of similarity the publications which share to each citation. Definition of co-citation is to finding the relationship of two publication which cited to each by another paper (Wang et al., 2016) As indicated in Figure 3(b) Paper C and Paper D are co-cited by Paper A, and Paper B. So, Paper C and Paper D have cocitation strength of 2. Also Citation and Bibliographic coupling is shown in Figure 3(a) and Figure 3(c), respectively. Bibliographic coupling employ in citation analysis to make a similarity relationship between papers is a similar measure as co-citation (Wang et al., 2016).

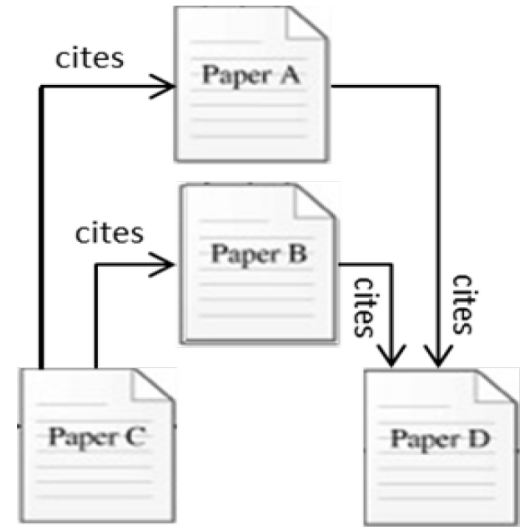

a

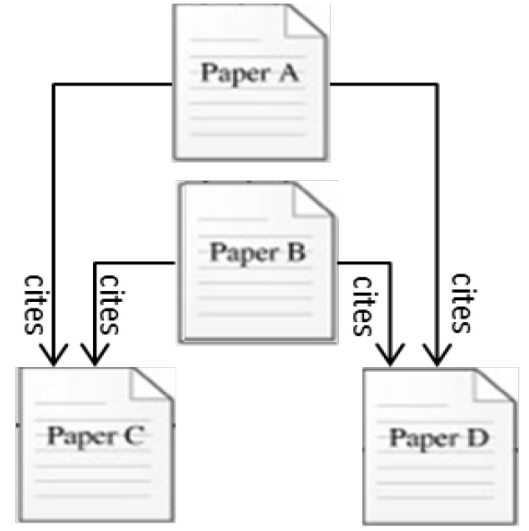

b

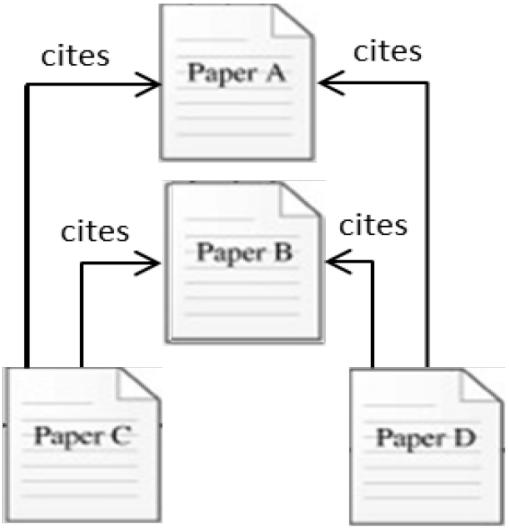

C

Figure 3. Citation relationship (a), Co-citation relationship (b) and Bibliographic coupling(c)

The "NET" file which generated by BibExcel use for co-citation analysis. This file open by Gephi software, the information of "NET" file is enough for network topology diagrams. When for first time “.NET" file open in Gephi the location of nodes/papers decided by Gephi randomly. The default lay out of software is "Force Atlas", this layout is high recommended layout for easy to understanding. The statistics data can export to "SPSS software" or Microsoft Excel directly for recheck. Manual adjusting such as move in $x$ or $y$ direction, spin around, setting the size of node, arrow and edges, repulsion strength, speed and gravity are available. 


\subsubsection{Publication Classification with Clustering Method}

Clustering is one the most critical approach in data mining analysis, clustering means the data fall into same module/cluster with more similarity than other (Chen \& He, 2016). The case of our study, where represented papers in the citation network is indicated in a group with same research field, a cluster can be identified, into the cluster the density of edge and arrow is high. There are many fields that clustering algorithm extended in them, for example genetic engineering, customer segmentation and publication analysis, normally these type data are numerical and classified attributes (Hsu \& Chen, 2007). The optimization of modularity tools in Gephi is under Louvain method, an iterative method to optimized modularity as the algorithm progresses. Modularity index is defined between -1 and 1 which present the density of edges inside due to outside of communities. According to (Uchimaru et al., 2015) modularity index is defined as:

$$
Q=\frac{1}{2 m} \sum_{i j}\left[A_{i j}-\frac{k_{i} k_{j}}{2 m}\right] \delta\left(c_{i}, c_{j}\right) .
$$

Here

$k_{j}=\sum_{i} A_{i j}$ is sum of link weight penetrating node $i, k_{i}=\sum_{j} A_{i j}$ is sum of link weight penetrating node $j$. The "Kronecker" delta $\delta\left(c_{i}, c_{j}\right)$ is 1 and 0 when nodes $i$ and $j$ are assigned to the same community and $m=(1 / 2) \sum_{i j} A_{i j}$

With using of Force Atlas (as discussion in 4.3 section), all connected nods move to the middle of the network, also the isolated nods move to the corners. With excluding outlier nodes in our network, it will remains with total of 233 node out of 1610 nodes. 


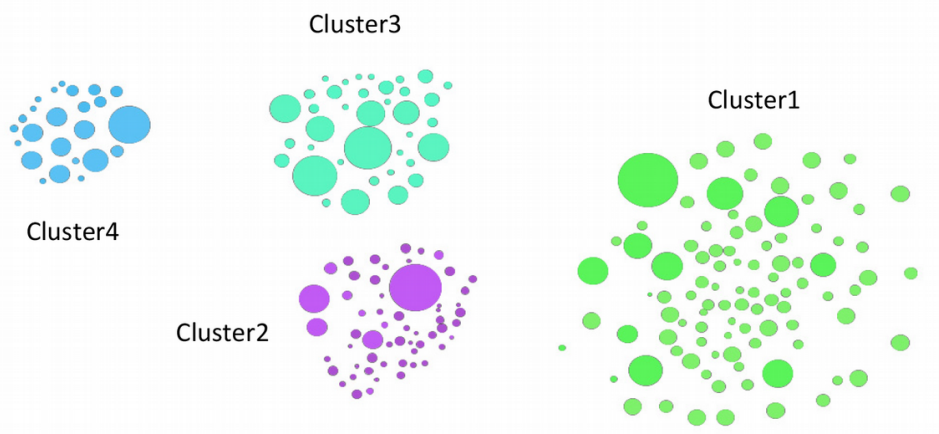

(a)

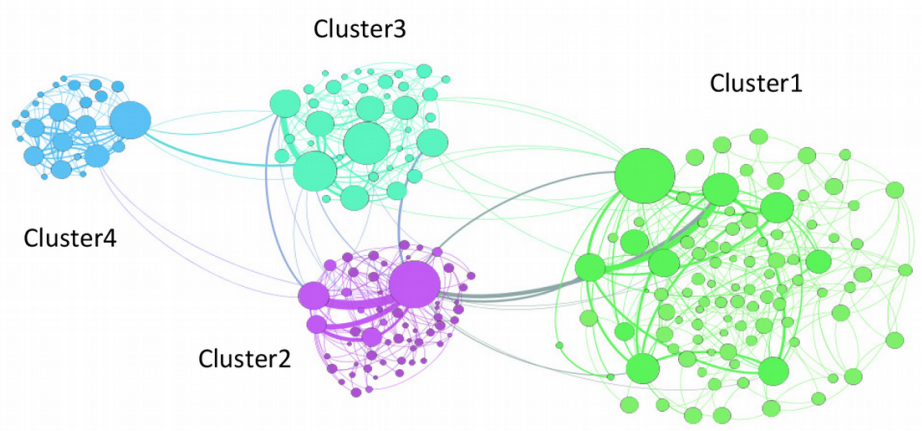

(b)

Figure 4. (a) The positioning of the four clusters without arc, (b) The positioning of the four clusters with arc 


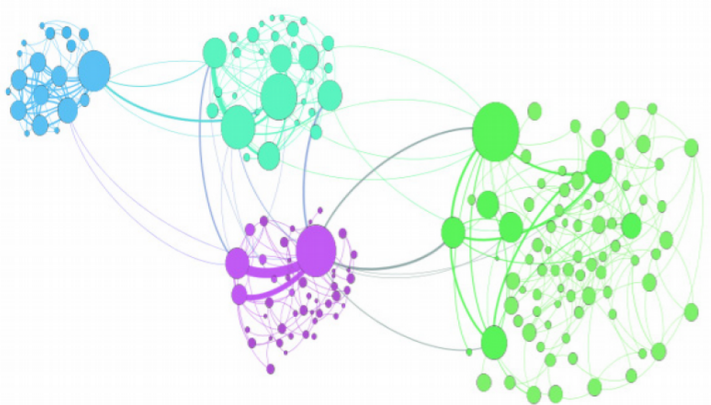

Clusters position in 2012

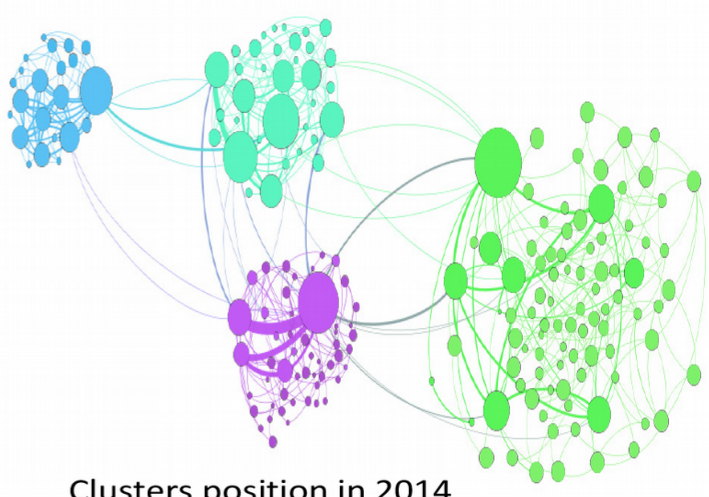

Clusters position in 2014
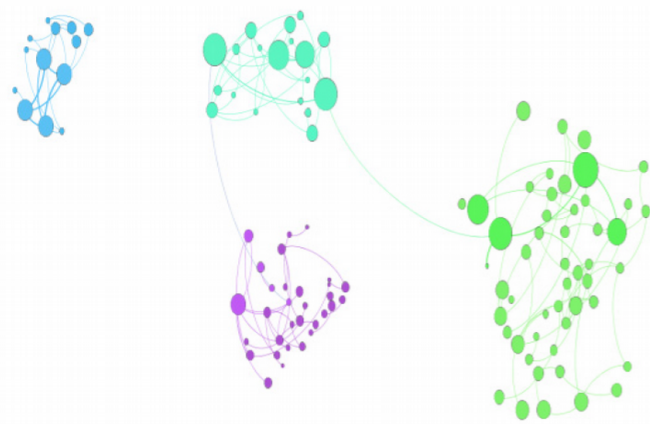

Clusters position in 2008
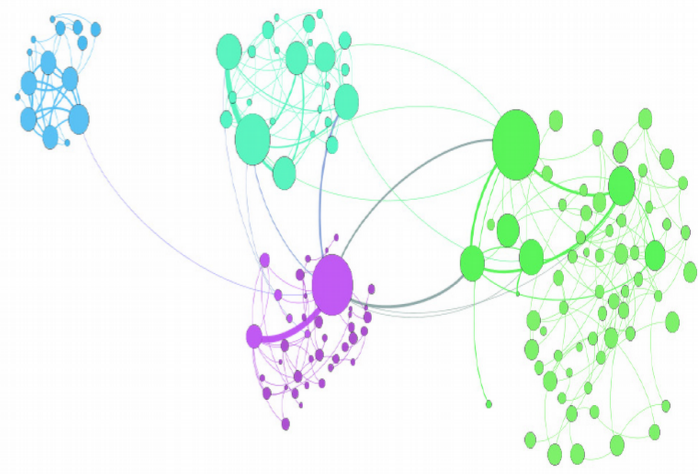

Clusters position in 2010

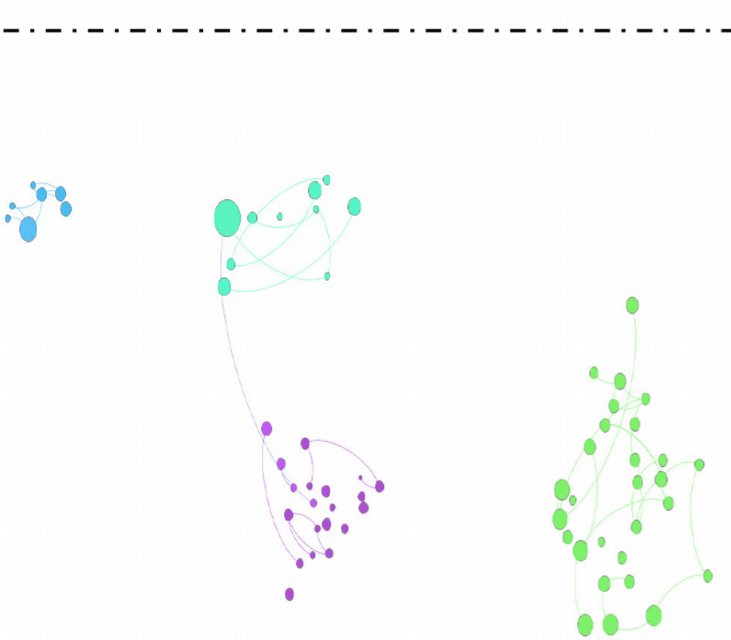

Clusters position in 2004
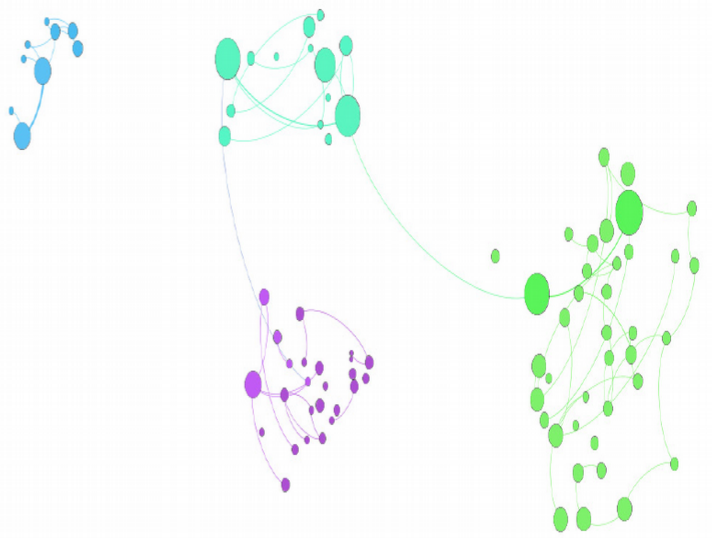

Clusters position in 2006

Figure 5. The evolution of clusters positions over time

Applying clustering algorithm on the 233 node presented four main clusters which show in Table 11 . These clusters have a set the underlying basis in optimization in supply chain management research and 
providing the field with the fundamental knowledge, concepts, techniques, theories, applications and utilities. The number of publications in different clusters varies from 24 to 115 papers. The $4^{\text {th }}$ cluster with 115 nodes/papers is the largest cluster and first cluster with 20 nodes/papers is smallest module. Figure $4(\mathrm{a} \& \mathrm{~b})$ shows the positioning of the four clusters with/without arcs.

Publications in same cluster usually have robust co-citation connection and often these papers present in same topic field. So the accurate analysis of publication of a cluster can conduct our study to reach the field of the cluster (Fahimnia et al., 2015). In order to find out the research area of each cluster we consider top publications with high value PageRank. The topical reference as publication classification is showing in Table 10, the senior scholars in first cluster included (Cortinhal, Lopes \& Melo, 2015), (Pishvaee \& Torabi, 2010) and (Santoso, Ahmed, Goetschalckx \& Shapiro, 2005). The labeling for this cluster as major research filed is "Network design, Mathematical modeling, and Optimization approach". Table 11 (Cluster 1-3) indicated the enabling of jointly sustainable economic development, conceptual analysis and experimental study which researchers have more desire to concentrated in optimization in supply chain management. Sure this conclusion will not appear without modeling and design strategy (Cluster 4). The number of publications in second cluster is half of the first cluster, lead papers included (Accorsi, Cascini, Cholette, Manzini \& Mora, 2014), (Pishvaee, Razmi \& Torabi, 2014) and (Grossmann \& Guillén-Gosálbez, 2010). Environmental impact assessment is the term which we use for labeling of this cluster. With monitoring of four major clusters (Cluster 1-4) shows, identifying real problems statement in an organization, practical problem solving and prescriptive analytics received less consideration by researchers. This result also applied by some review publication such as (Melo et al., 2009), (Eskandarpour et al., 2015) and (Fahimnia, Farahani, Marian \& Luong, 2013). So, the initial result of this classification is the opportunity for conduct the future survey in formal modelling of optimization in supply chain management to practical/operation effort. Although some recent researcher focused near to this gap, for example (Suzuki, 2016) and (Han \& Kim, 2016), but it is clear that all these efforts cannot be capture by our four clusters.

\begin{tabular}{|c|r|l|}
\hline Cluster & Number of publication & \multicolumn{1}{|c|}{ Cluster labeling } \\
\hline $1^{\text {st }}$ & 115 & $\begin{array}{l}\text { Network design, mathematical modeling, Optimization approach }- \text { Conceptual } \\
\text { analysis to reveal descriptive studies }\end{array}$ \\
\hline $2^{\text {nd }}$ & 57 & $\begin{array}{l}\text { Environmental sustainability, Lifecycle assessment, Green/Sustainable supply chain - } \\
\text { Assessing the environmental impact }\end{array}$ \\
\hline $3^{\text {rd }}$ & 24 & $\begin{array}{l}\text { Operational planning, logistics systems, inventory - Experimental study } \\
\text { program }\end{array}$ \\
\hline $4^{\text {th }}$ & 2 & \\
\hline
\end{tabular}

Table 11. The four main clusters and related in our study 
The Clusters 1 and 4 overlap with modeling development, Cluster 4 focuses on strategy design pattern and theory development with creating new modeling. Many relevant strategic decisions in supply chain management such as: located of plants, transportation modes and distribution centers are located in this cluster. In Cluster 1 focuses on analytical computations by the evaluating data, taking new established analysis and integrated supply chain design model. Nearly the most publications in first cluster are older paper due to other clusters, we expected in next decade the second cluster will grow up faster and the gap between our two popular clusters (Cluster 1 and Cluster 2) become less.

\subsubsection{Evolution of Clusters Over Years}

To help understand the evolution of optimization in supply chain management evaluation over time, we also complete a dynamic co-citation analysis covering all papers in the four clusters. The evolution is graphically presented in Figure 5. The size of a circle represents the PageRank value of each paper, so the larger the size of a circle, the more highly-cited and prestigious the corresponding paper. It can be expected that the research papers in Clusters 3 and 4 will continue to grow in next decade and in other side we see stabilize in Clusters 1 and 2.

\section{Conclusion and Some Suggestions for Future Study}

This paper provided a systematic analyzed review of optimization within context the supply chain management. There are many literature reviews published within the scope of this topic, but there are a handful of researchers involved in bibliometric and network analysis to evaluate information and data clustering. Moreover, in this paper we identified classification, characterized and labeled our data (section 4.3.1) to show which part of this topic has been paid more attention, or rarely considered by researchers to guide the further investigation and strengthen SCM planning needs.

Based on our bibliometric analysis, our initial efforts presented the geographical global map. The dispersion of affiliation represented by Western Europe and North America has impressive publications, with Asia not very far behind. Perhaps in near future the rate of diffusion of the jobs will increase rapidly. Looking to Table 6, this shows that 9 out of 17 top institutions belong to Asia (Turkey not included), while countries such as Iran, Taiwan, Singapore and china have more contributions. With this map and the information displayed in Table 6, the students and scholars who are interested in this topic could conduct their research at various institutes. 
Furthermore, we found out that the majority of significant papers were publishing at the beginning of the last decade. Considering Figure 1 it is not surprising to see that in 2010 we faced a high rate of increase in publications regarding the supply chain management area. International Journal of Production Economics and European Journal of Operational Research are more popular journals in this field; we see that many scholars in United States and Asia attend to publish their papers in European journals.

Our network analysis conclusion shows that, optimization in supply chain management can be divided into four clusters/categories, labeling of the popular cluster (Cluster 1) is: Conceptual analysis and analytical modeling. We recognize that facility optimization problem may be getting saturated in this field. The name of the second cluster, which is far behind is: Environmental sustainability and green supply chain network, articles which were published in this cluster are younger compared to the first cluster; it seems that green supply chain could be as an emerging area, as our research result experimental study and design strategy pays less attention in to this topic.

However, this type of research has some limitations and needs further investigations.

First, designing "Key words search model" to ensure capturing the most effective keywords and field area. We can make a pool of papers but we should be sure to maximize coverage in our research. It is fundamental approach for this type review. Second, bibliometric and network analyzing is associated with a huge number of papers, so using professional software to enhance reliable results is necessary. Third, database plays the main role in systematic review, hence the importance of database should be considered, Scopus is relatively comprehensive due to others (Wang \& Waltman, 2016), so to achieve suitable advantage, this database is suggested. We believe this paper can create an objective and professional understanding in order to navigate the further mapping and direction for broaden research.

\section{Acknowledgement}

Kindly special thanks to Prof. Zheng Jian Qiao for precious editorial contributions to improve the presentation of this paper. 


\section{References}

Accorsi, R., Cascini, A., Cholette, S., Manzini, R., \& Mora, C. (2014). Economic and environmental assessment of reusable plastic containers: A food catering supply chain case study. International Journal of Production Economics, 152, 88-101. http://dx.doi.org/10.1016/j.ijpe.2013.12.014

Altiparmak, F., Gen, M., Lin, L., \& Paksoy, T. (2006). A genetic algorithm approach for multi-objective optimization of supply chain networks. Computers \& Industrial Engineering, 51(1), 196-215. http://dx.doi.org/10.1016/j.cie.2006.07.011

Amiri, A. (2006). Designing a distribution network in a supply chain system: Formulation and efficient solution procedure. European Journal of Operational Research, 171(2), 567-576. http://dx. doi. org/10. 1016/j. ejor. 2004. 09.018

Artto, K., Martinsuo, M., Gemünden, H.G., \& Murtoaro, J. (2009). Foundations of program management: A bibliometric view. International Journal of Project Management, 27(1), 1-18.

http://dx.doi.org/10.1016/j.ijproman.2007.10.007

Aust, G., \& Buscher, U. (2014). Cooperative advertising models in supply chain management: A review. European Journal of Operational Research, 234(1), 1-14. http://dx.doi.org/10.1016/j.ejor.2013.08.010

Awudu, I., \& Zhang, J. (2012). Uncertainties and sustainability concepts in biofuel supply chain management: A review. Renewable and Sustainable Energy Reviews, 16(2), 1359-1368. http://dx.doi.org/10.1016/j.rser.2011.10.016

Batagelj, V., \& Mrvar, A. (2011). Pajek - Program for Analysis and Visualization of Large Networks Reference Manual: List of Commands with Short Explanation. Version 2. 05. Ljubljana, Slovenia.

Beiler, M.O. (2016). Organizational sustainability in transportation planning: Evaluation of multijurisdictional agency collaboration. Journal of Transport Geography, 52, 29-37.

http://dx.doi.org/10.1016/j.jtrangeo.2016.02.013

Borodin, A., Roberts, G.O., Rosenthal, J.S., \& Tsaparas, P. (2005). Link analysis ranking algorithms, theory, and experiments. ACM Transaction on Internet Technologies, 5, 231-297

http://dx.doi.org/10.1145/1052934.1052942

Buckley, C., \& Voorhees, E.M. (2005). Retrieval system evaluation. MIT Press.

Chen, D., Liu, Z., Luo, Z., Webber, M., \& Chen, J. (2016). Bibliometric and visualized analysis of emergy research. Ecological Engineering, 90, 285-293. http://dx.doi.org/10.1016/j.ecoleng.2016.01.026 
Chen, J.-Y., \& He, H.-H. (2016). A fast density-based data stream clustering algorithm with cluster centers self-determined for mixed data. Information Sciences, 345, 271-293. http://dx.doi.org/10.1016/j.ins.2016.01.071

Chopra, S., \& Meindl, P. (2004). Supply Chain Management. Strategy, Planning \& Operation (2nd ed.). Pearson Prentice-Hall.

Cortinhal, M.J., Lopes, M.J., \& Melo, M.T. (2015). Dynamic design and re-design of multi-echelon, multiproduct logistics networks with outsourcing opportunities: A computational study. Computers \& Industrial Engineering, 90, 118-131. http://dx.doi.org/10.1016/j.cie.2015.08.019

Costa, A., Celano, G., Fichera, S., \& Trovato, E. (2010). A new efficient encoding/decoding procedure for the design of a supply chain network with genetic algorithms. Computers \& Industrial Engineering, 59(4), 986-999. http://dx.doi.org/10.1016/j.cie.2010.09.011

Dabbene, F., Gay, P., \& Tortia, C. (2014). Traceability issues in food supply chain management: A review. Biosystems Engineering, 120, 65-80. http://dx.doi.org/10.1016/j.biosystemseng.2013.09.006

Dabkowski, M., Breiger, R., \& Szidarovszky, F. (2015). Simultaneous-direct blockmodeling for multiple relations in Pajek. Social Networks, 40,1-16. http://dx.doi.org/10.1016/j.socnet.2014.06.003

Doreian, P. (2006). Exploratory Social Network Analysis with Pajek, W. de Nooy, A. Mrvar, V. Batagelj. Cambridge University Press, New York (2005). Social Networks, 28(3), 269-274. http://dx.doi.org/10.1016/j.socnet.2005.12.002

Eskandarpour, M., Dejax, P., Miemczyk, J., \& Péton, O. (2015). Sustainable supply chain network design: An optimization-oriented review. Omega, 54, 11-32. http://dx.doi.org/10.1016/j.omega.2015.01.006

Fabbe-Costes, N., \& Jahre, M. (2008). Supply chain integration and performance: a review of the evidence. International Journal of Logistics Management, 19(2), 130-154.

http://dx.doi.org/10.1108/09574090810895933

Fahimnia, B., Farahani, R.Z., Marian, R., \& Luong, L. (2013). A review and critique on integrated production-distribution planning models and techniques. Journal of Manufacturing Systems, 32(1), 1-19. http://dx.doi.org/10.1016/j.jmsy.2012.07.005

Fahimnia, B., Sarkis, J., \& Davarzani, H. (2015). Green supply chain management: A review and bibliometric analysis. International Journal of Production Economics, 162, 101-114. http://dx.doi.org/10.1016/j.ijpe.2015.01.003

Farahani, R.Z., Rezapour, S., Drezner, T., \& Fallah, S. (2014). Competitive supply chain network design: An overview of classifications, models, solution techniques and applications. Omega, 45, 92-118. http://dx.doi.org/10.1016/j.omega.2013.08.006 
Gajdoš, P., Ježowicz, T., Uher, V., \& Dohnálek, P. (2016). A parallel Fruchterman-Reingold algorithm optimized for fast visualization of large graphs and swarms of data. Swarm and Evolutionary Computation, 26, 56-63. http://dx.doi.org/10.1016/j.swevo.2015.07.006

Garfield, E. (2009). From the science of science to Scientometrics visualizing the history of science with HistCite software. Journal of Informetrics, 3(3), 173-179. http://dx.doi.org/10.1016/j.joi.2009.03.009

Gephi (2013). Gephi makes graph handy.

Gomez-Jauregui, V., Gomez-Jauregui, C., Manchado, C., \& Otero, C. (2014). Information management and improvement of citation indices. International Journal of Information Management, 34(2), 257-271. http://dx.doi.org/10.1016/j.ijinfomgt.2014.01.002

González-Pereira, B., Guerrero-Bote, V.P., \& Moya-Anegón, F. (2010). A new approach to the metric of journals' scientific prestige: The SJR indicator. Journal of Informetrics, 4(3), 379-391. http://dx.doi.org/10.1016/j.joi.2010.03.002

Grieger, M. (2003). Electronic marketplaces: A literature review and a call for supply chain management research. European Journal of Operational Research, 144(2), 280-294. http://dx.doi.org/10.1016/S03772217(02)00394-6

Grossmann, I.E., \& Guillén-Gosálbez, G. (2010). Scope for the application of mathematical programming techniques in the synthesis and planning of sustainable processes. Computers \& Chemical Engineering, 34(9), 1365-1376. http://dx.doi.org/10.1016/j.compchemeng.2009.11.012

Gu, J.X., Goetschalckx, M., \& McGinnis, L.F. (2007). Research on warehouse operation: A comprehensive review. European Journal of Operational Research, 177(1), 1-21.

http://dx.doi.org/10.1016/j.ejor.2006.02.025

Gunasekaran, A., \& Ngaib, E.W.T. (2005). Build-to-order supply chain management: a literature review and framework for development. Journal of Operations Management, 23(5), 423-451. http://dx.doi.org/10.1016/j.jom.2004.10.005

Gupta, S., \& Palsule-Desai, O. (2011). Sustainable supply chain management: Review and research opportunities. IIMB Management Review, 23(4), 234-245. http://dx.doi.org/10.1016/j.iimb.2011.09.002

Hall, C.M. (2011). Publish and perish? Bibliometric analysis, journal ranking and the assessment of research quality in tourism. Tourism Management, 32(1), 16-27. http://dx.doi.org/10.1016/j.tourman.2010.07.001 
Han, J.-H., \& Kim, Y.-D. (2016). Design and operation of a two-level supply chain for production-timedependent products using Lagrangian relaxation. Computers \& Industrial Engineering, 96, 118-125. http://dx.doi.org/10.1016/j.cie.2016.03.018

Hsu, C.-C., \& Chen, Y.-C. (2007). Mining of mixed data with application to catalog marketing. Expert Systems with Applications, 32(1), 12-23. http://dx.doi.org/10.1016/j.eswa.2005.11.017

Huang, X., Huang, Y., Wen, M., An, A., Liu, Y., \& Poon, J. (2006). Applying data mining to pseudo-relevance feedback for high performance text retrieval. Proceeding of the 6th IEEE international conference on data mining. 295-306. http://dx.doi.org/10.1109/icdm.2006.22

Hugo, A., \& Pistikopoulos, E.N. (2005). Environmentally conscious long-range planning and design of supply chain networks. Journal of Cleaner Production, 13(15), 1471-1491.

http://dx.doi.org/10.1016/j.jclepro.2005.04.011

Huscroft, J.R., Hazen, B.T., Hall, D.J., Skipper, J.B., \& Hanna, J.B. (2013). Reverse logistics: past research, current management issues, and future directions. International Journal of Logistics Management, 24(3), 304-327. http://dx.doi.org/10.1108/iilm-04-2012-0024

Jie, L., Xiaohong, G., Shifei, S., \& Jovanovic, A. (2014). Bibliometric Mapping of "International Symposium on Safety Science and Technology (1998-2012)". Procedia Engineering, 84, 70-79. http://dx.doi.org/10.1016/j.proeng.2014.10.411

Kaufmann, L., \& Gaeckler, J. (2015). A structured review of partial least squares in supply chain management research. Journal of Purchasing and Supply Management, 21, 259-272. http://dx.doi.org/10.1016/j.pursup.2015.04.005

Kleinberg, J. (1999). Authoritative sources in a hyperlinked environment. Journal of ACM, 46, 604-632. http://dx.doi.org/10.1145/324133.324140

Kundu, A., Jain, V., Kumar, S., \& Chandra, C. (2015). A journey from normative to behavioral operations in supply chain management: A review using Latent Semantic Analysis. Expert Systems with Applications, 42, 796-809. http://dx.doi.org/10.1016/j.eswa.2014.08.035

Lu, W, \& Yuan, H. (2011). A framework for understanding waste management studies in construction. Waste Management, 31(6), 1252-1260. http://dx.doi.org/10.1016/j.wasman.2011.01.018

Madenasa, N., Tiwaria, A., Turner, C., \& Woodward, J. (2014). Information flow in supply chain management: A review across the product lifecycle. CIRP Journal of Manufacturing Science and Technology, 7, 335-346. http://dx.doi.org/10.1016/j.cirpj.2014.07.002 
Marra, M., Ho, W., \& Edwards, J. (2012). Supply chain knowledge management: A literature review. Expert Systems with Applications, 39(5), 6103-6110. http://dx.doi.org/10.1016/j.eswa.2011.11.035

Martínez-Jurado, P.J., \& Moyano-Fuentes, J. (2014). Lean Management, Supply Chain Management and Sustainability. Journal of Cleaner Production, 85, 134-150. http://dx.doi.org/10.1016/j.jclepro.2013.09.042

Meixell, M.J., \& Norbis, M. (2008). A review of the transportation mode choice and carrier selection literature. International Journal of Logistics Management, 19(2), 183-211. http://dx.doi.org/10.1108/09574090810895951

Melo, M.T., Nickel, S., \& Saldanha-da-Gama, F. (2009). Facility location and supply chain management A review. European Journal of Operational Research, 196(2), 401-412. http://dx.doi.org/10.1016/j.ejor.2008.05.007

Papageorgiou, L.G. (2009). Supply chain optimisation for the process industries: Advances and opportunities. Computers \& Chemical Engineering, 33(12), 1931-1938. http://dx.doi.org/10.1016/j.compchemeng.2009.06.014

Pazhani, S., Ventura, J.A., \& Mendoza, A. (2016). A serial inventory system with supplier selection and order quantity allocation considering transportation costs. Applied Mathematical Modelling, 40(1), 612-634. http://dx.doi.org/10.1016/j.apm.2015.06.008

Pishvaee, M.S., Razmi, J., \& Torabi, S.A. (2014). An accelerated Benders decomposition algorithm for sustainable supply chain network design under uncertainty: A case study of medical needle and syringe supply chain. Transportation Research Part E: Logistics and Transportation Review, 67, 14-38. http://dx.doi.org/10.1016/j.tre.2014.04.001

Pishvaee, M.S., \& Torabi, S.A. (2010). A possibilistic programming approach for closed-loop supply chain network design under uncertainty. Furæy Sets and Systems, 161(20), 2668-2683.

http://dx.doi.org/10.1016/j.Fss.2010.04.010

Ponomarov, S.Y., \& Holcomb, M.C. (2009). Understanding the concept of supply chain resilience. International Journal of Logistics Management, 20(1), 124-143. http://dx.doi.org/10.1108/09574090910954873

Prakash, A., \& Deshmukh, S.G. (2011). A multi-criteria customer allocation problem in supply chain environment: An artificial immune system with fuzzy logic controller based approach. Expert Systems with Applications, 38(4), 3199-3208. http://dx.doi.org/10.1016/j.eswa.2010.09.008

Santoso, T., Ahmed, S., Goetschalckx, M., \& Shapiro, A. (2005). A stochastic programming approach for supply chain network design under uncertainty. European Journal of Operational Research, 167(1), 96-115. http://dx.doi.org/10.1016/j.ejor.2004.01.046 
Sarkis, J., Zhu, Q., \& Lai, K.-H. (2011). An organizational theoretic review of green supply chain management literature. International Journal of Production Economics, 130(1), 1-15. http://dx.doi.org/10.1016/j.ijpe.2010.11.010

Saunders. M., Lewis. P., \& Thornhill, A. (2009). Research Methods for Business Students. Pearson, Harlow.

Seuring, S., \& Müller, M. (2008). From a literature review to a conceptual framework for sustainable supply chain management. Journal of Cleaner Production, 16(15), 1699-1710, Sustainability and Supply Chain Management. http://dx.doi.org/10.1016/j.jclepro.2008.04.020

Small, H. (1973). Co-citation in the scientific literature: a new measure of the relationship between two documents. Journal of the American Society for Information Science, 24, 265-269. http://dx.doi.org/10.1002/asi.4630240406

Stefanovic, D., Stefanovic, N., \& Radenkovic, B. (2009). Supply network modelling and simulation methodology. Simul. Model. Pract. Theory, 17(4), 743-766. http://dx.doi.org/10.1016/j.simpat.2009.01.001

Su, M., Chen, C., \& Yang, Z. (2016). Urban energy structure optimization at the sector scale: considering environmental impact based on life cycle assessment. Journal of Cleaner Production, 112(2), 1464-1474. http://dx.doi.org/10.1016/j.jclepro.2015.01.059

Suzuki, Y. (2016). A dual-objective metaheuristic approach to solve practical pollution routing problem. International Journal of Production Economics, 176, 143-153. http://dx.doi.org/10.1016/j.ijpe.2016.03. 008

Uchimaru, T., Hazama, K., Fujiwara, K., \& Kano, M. (2015). Nearest Correlation Louvain Method for Fast and Good Selection of Input Variables of Statistical Model*. IFAC-PapersOnLine, 48(8), 123-128. http://dx.doi.org/10.1016/j.j.facol.2015.08.168

Wang, N., Liang, H., Jia, Y., Ge, S., Xue, Y., \& Wang, Z. (2016) Cloud computing research in the IS discipline: A citation/co-citation analysis. Decision Support Systems, 86, 35-47. http://dx.doi.org/10.1016/j.dss.2016.03.006

Wang, Q., \& Waltman, L. (2016). Large-scale analysis of the accuracy of the journal classification systems of Web of Science and Scopus. Journal of Informetrics, 10(2), 347-364.

http://dx.doi.org/10.1016/j.joi.2016.02.003

Wang, Y., Wallacen, S., Shen, B., \& Choi, T.-M. (2015). Service supply chain management: A review of operational models European Journal of Operational Research, 247(3), 685-698. 
Wehbe, F., Hattab, M.A., \& Hamzeh, F. (2016). Exploring associations between resilience and construction safety performance in safety networks. Safety Science, 82, 338-351. http://dx.doi.org/10.1016/j.ssci.2015.10.006

Yang, G.F., Wang, Z.P., \& Li, X.Q. (2009). The optimization of the closed-loop supply chain network. Transportation Research Part E-Logistics and Transportation Review, 45(1), 16-28. http://dx.doi.org/10.1016/j.tre.2008.02.007

Yin, X., Huang, J.X., \& Li, Z. (2011). Mining and modeling linkage information from citation context for improving biomedical literature retrieval. Information Processing \& Management, 47(1), 53-67. http://dx.doi.org/10.1016/j.ipm.2010.03.010

Journal of Industrial Engineering and Management, 2016 (www.jiem.org)

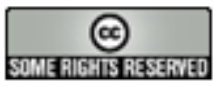

Article's contents are provided on an Attribution-Non Commercial 3.0 Creative commons license. Readers are allowed to copy, distribute and communicate article's contents, provided the author's and Journal of Industrial Engineering and Management's names are included. It must not be used for commercial purposes. To see the complete license contents, please visit http://creativecommons.org/licenses/by-nc/3.0/. 